\title{
Training in de urologie: vroeger en nu. Visie van het Concilium Urologicum
}

\author{
A. A. B. Lycklama à Nijeholt ${ }^{1}$ W. Hirdes ${ }^{1}$
}

Published online: 9 November 2016

(c) The Author(s) 2016. This article is available at SpringerLink with Open Access.

Samenvatting In dit stuk staan we stil bij alle vele ontwikkelingen die al plaats hebben gevonden in de opleiding tot uroloog in het afgelopen decennium, zoals de vaststelling van het Curriculum Urologie met de CANMEDS-competenties en het landelijke cursorisch onderwijs. Ook blikken we vooruit op wat gaat komen: competentiegericht opleiden, verkorting van de opleidingsduur en integratie van subspecialisatie.

Trefwoorden opleiding $\cdot$ curriculum $\cdot$ cursorisch onderwijs

\section{Training in Urology, past, present and future}

\begin{abstract}
In this article two chairmen of the Concilium Urologicum (past and present) reflect on the urological training in the Netherlands as it is now and on future developments, like EPA's, shortening of the training program and subspecialisation.
\end{abstract}

Keywords urological training program - curriculum . cursory education

\section{Introductie}

(GLaN): Het opleiden van aios urologie gebeurt in de acht clusters, die zijn gegroepeerd om de acht academische centra in Nederland. Momenteel wordt het 'Curriculum voor de

prof. dr. A. A. B. Lycklama à Nijeholt

aablycklama@gmail.com

1 Concilium Urologicum, Leiden, Nederland opleiding Urologie' door een commissie, die door het Concilium is ingesteld, onder voorzitterschap van prof. Eric Meuleman, volledig herschreven. Dit vindt plaats terwijl het huidige curriculum, aangenomen op de ledenvergadering van de NVU in november 2009, nog geen zeven jaar oud is.

Om te kunnen begrijpen hoe we tegen verleden, heden en toekomst van 'Training in de Urologie' moeten aankijken, is het goed om te inventariseren welke essenties de basis vormden voor het huidige curriculum. De 'Werkgroep Curriculum', onder voorzitterschap van Jan Blom, ging uit van het verdwijnen van de algemene uroloog, de uroloog die alles van het vakgebied beheerst. Er werd uitgegaan van superspecialisatie: in de andrologische urologie, functionele urologie, inclusief female urology, kinderurologie, oncologische urologie, minimaal invasieve urologie en transplantatie-urologie. Een ander belangrijk element van het huidige curriculum was de implementatie van de zeven CANMEDS-competenties: Medisch handelen, Communicatie, Samenwerking, Kennis en wetenschap, Maatschappelijk handelen, Organisatie en Professionaliteit. Enerzijds werd algemeen het belang onderkend van een brede vorming tijdens de opleiding, anderzijds werd het risico gezien dat een voor een chirurgisch vak essentieel onderdeel, namelijk praktische scholing (als onderdeel van medisch handelen), minder prioriteit zou krijgen. In het curriculum is, onderverdeeld in thema's, beschreven wat de aios moet leren. Om de competenties te concretiseren, zijn voor elk thema zogenaamde kritische beroepssituaties geformuleerd. De vorderingen van de aios worden getoetst met Korte Praktijk Beoordelingen (KPB's) en wat betreft de operatieve vaardigheden middels Objective Structured Assessment of Technical Skills (OSATS). Het aan het curriculum gekoppelde landelijke en lokale onderwijs bestaat uit theoretische en praktische cursussen. Het Concilium Urologicum en de 
Tabel 1 Praktische cursussen van het Urologisch Opleidingsinstituut (UOI).

\begin{tabular}{lll}
\hline cursus & te volgen in opleidingsjaar & frequentie van aanbod \\
\hline anatomie retroperitoneum & vierde jaar & jaarlijks \\
anatomie kleine bekken & derde jaar & jaarlijks \\
functionele urologie/urodynamica & derde of vierde jaar & 1x per 2 jaar (2 dagen) \\
laparoscopie & derde jaar & jaarlijks \\
stralingshygiëne & ieder jaar mogelijk & jaarlijks \\
UVO: urologisch vaardigheidsonderwijs & ieder jaar in diverse modules & jaarlijks \\
\hline
\end{tabular}

Commissie Cursorisch Onderwijs (CCO) zijn verantwoordelijk voor het vakinhoudelijke deel van deze cursussen.

Door de CCO wordt verplicht landelijk theoretisch onderwijs voor aios georganiseerd. Daarnaast wordt door het Urologisch Opleidingsinstituut (UOI), namens het CCO, een aantal praktische cursussen georganiseerd. De cursussen in het huidige curriculum staan beschreven in tab. 1 .

\section{Nieuwe ontwikkelingen op het gebied van cursorisch onderwijs}

In de afgelopen jaren zijn twee innoverende initiatieven op het gebied van met name praktisch cursorisch onderwijs van harte door het Concilium Urologicum omarmd, namelijk de 'Upfront cursus' en het '40-uren project'.

Allereerst wordt sinds 2009 de Upfront cursus georganiseerd in december. Deze tweedaagse cursus is bedoeld voor aios die een maand later beginnen met hun urologische deel van de opleiding. Met name de groei van de laparoscopie binnen de minimaal invasieve urologie, onderstreepte in de afgelopen jaren de noodzaak van de ontwikkeling van deze cursus. Een belangrijk aspect bij deze cursus is een certificaat op het gebied van laparoscopie, dat de aios moet halen als afronding van deze cursus. Destijds is met de Inspectie voor de Gezondheidszorg (IGZ) besproken dat aios pas tijdens de urologie-opleiding mogen participeren in laparoscopische ingrepen, als zij bewezen hebben voldoende bekwaam te zijn in een aantal basisvaardigheden. Dit is ingesteld om te voorkomen dat, met het oog op patiëntveiligheid, deze basisvaardigheden verworven zouden moeten worden tijdens operaties bij patiënten. Het Concilium Chirurgicum heeft destijds goedgekeurd dat deze cursus in de heelkundeperiode kan plaatsvinden en dat deelnemende aios in aanmerking komen voor vrijstelling van werk en vergoeding van cursuskosten vanuit de Heelkunde.

Een ander belangrijk innoverend project was het 40-uren project dat in het kader van 'training in de urologie' enige jaren geleden is opgezet. Hoewel binnen het Concilium in de beginjaren veel discussie is geweest over de uitwerking van dit project, is steeds onderkend dat de opzet hiervan een belangrijke bijdrage kan leveren aan de met name praktische scholing van aios. Dit is ook reden geweest dat medio 2012 door het Concilium is besloten aan dit project een verplicht karakter toe te kennen. Dit betekende dat aios verplicht werden deze cursus te volgen en dat de aios de cursuskosten konden declareren in het opleidingsziekenhuis. Met enige trots is dit project begin 2012, middels een gezamenlijke brief van Ad Hendrikx namens de Werkgroep Training in de Urologie, en de voorzitter van het Concilium Urologicum, aan de Raad Opleiding voorgelegd. In deze Raad Opleiding zijn alle specialistische verenigingen vertegenwoordigd. In de brief werd gesteld dat met dit opleidingsplan de Urologie model kan staan voor implementatie van op landelijk niveau gecoördineerd vaardigheidsen technologieonderwijs en tevens als model zou kunnen dienen voor bijvoorbeeld de chirurgen en de gynaecologen. De voorzitter destijds van de Raad Opleiding, prof. dr. Joep Dörr, sprak duidelijk zijn waardering uit voor dit initiatief. Wel viel destijds ook landelijk op dat in de diverse opleidingsklinieken de urologische begroting voor het cursorisch onderwijs vanwege het 40-uren project flink opliep, hetgeen ook tot discussie in de Raad Opleiding aanleiding heeft gegeven.

$\mathrm{Na}$ de start van het 40-uren project als pilot, is in augustus 2013 binnen het Concilium het evaluatierapport 'Rapport training in urology' besproken [1]. Hierin werden de eerste acht modules in de eerste acht ziekenhuizen besproken. Op basis van deze eerste evaluatie adviseerde de CCO destijds om dit project verder landelijk in te voeren. Een belangrijke kanttekening in het evaluatierapport was dat modules waar nodig aangepast moesten worden. Daarom is destijds voor het maken en aanpassen van de modules een commissie binnen het Concilium ingesteld, de Commissie Urologisch Vaardigheids Onderwijs (CUVO). Het was inmiddels duidelijk dat met de invoering van het UVO (de nieuwe benaming van het 40 -uren project), overlap ging ontstaan met een aantal praktische cursussen. In verband hiermee werd het verplichte karakter van de echocursus, de endo-urologiecursus en de laser/elektrochirurgiecursus beëindigd. Inmiddels is de stand van zaken binnen het UVO een vast agendapunt bij de periodieke Conciliumvergaderingen. 


\section{De toekomst van het opleiden}

(WH): Als huidige voorzitter van het Concilium is mijn taak een en ander over de toekomst van de opleiding Urologie op papier te zetten. Een lastige opdracht voor iemand die ook in de urologie meer verleden dan toekomst heeft, geen waarzegger is en moet schrijven over ontwikkelingen die elkaar, zoals in het onderwijs gebruikelijk, sneller opvolgen dan zij geëvalueerd kunnen worden. Onderstaande is dan ook deels gebaseerd op feiten, deels op veronderstellingen en deels op persoonlijke wensen en ideeën. Aan $\mathrm{u}$ als kritische lezer om dit onderscheid te maken.

\section{Competenties}

Sinds 2002 is gewerkt aan het introduceren en implementeren van competentiegericht opleiden. Tot die tijd werden deze competenties vanzelfsprekend ook wel getoetst, maar dit was meer impliciet. 'Medisch handelen' was eigenlijk de enige (h)erkende competentie.

Andere competenties (hiervoor al genoemd door Guus Lycklama à Nijeholt) kwamen wel aan de orde, maar werden niet expliciet benoemd. Met name voor de algemene competenties, ook softe competenties genoemd, denk aan samenwerken, is het lang lastig gebleven (en het is misschien nog steeds wel lastig) om deze in het curriculum in te bouwen, terwijl tekortschietende communicatie toch regelmatig de bron van veel narigheid in de zorg is. Samenwerken, bijvoorbeeld binnen een multidisciplinair overleg (MDO) en tussen de eerste en de tweede lijn, is een absolute voorwaarde voor het organiseren en betaalbaar houden van de zorg in de toekomst. Veel jonge specialisten blijken aan het eind van de opleiding tekorten op dit gebied te ervaren; voor aios schijnen deze tekorten soms de oorzaak van een burn-out te zijn.

Er zijn veel oorzaken aan te geven voor het achterblijven van de inbedding van deze algemene competenties, zoals: onvoldoende concrete uitwerking in opleidingsplannen, onvoldoende houvast (of affiniteit met) voor opleiders(groepen), onvoldoende hulpmiddelen voor opleiders, etc, terwijl volgens het Kaderbesluit eind 2015 elke aios geschoold moest zijn in álle competenties.

In het kader van het in 2011 gestarte project 'CanBetter', dat onder andere als doel had de algemene competenties te concretiseren en daarmee een breder draagvlak te geven, is een aantal thema's geformuleerd waarvan de implementatie binnen de opleiding overwogen kan worden. Het betreft hier onderwerpen waarvan elke aios enige kennis zou moeten hebben en die voor geïnteresseerden een verdieping van of aanvulling op hun opleiding kunnen vormen. De thema's hebben betrekking op medisch leiderschap, doelmatigheid, ouderenzorg en patiëntveiligheid. De vraag is of hier een rol voor de NVU is weggelegd of dat dit meer op het terrein van bijvoorbeeld de COC's ligt, in het kader van discipline overstijgend onderwijs.

\section{Veranderingen die zich in korte tijd voltrekken}

Door veel opleiders en aios wordt, meer of minder uitgesproken, ervaren dat het specialisme Urologie, maar ook de opleiding, in een dermate hoog tempo verandert, door bijvoorbeeld de snelle opkomst van de minimaal invasieve en de robotchirurgie, dat het curriculum niet meer aansluit bij de praktijk.

Geaccepteerd is dat de kinderurologie niet meer voor alle urologen is. Inmiddels geldt echter hetzelfde voor de minimaal-invasieve chirurgie, de robotchirurgie, gecompliceerde steenbehandeling, maar ook voor complexe functionele of andrologische urologische behandelingen. De verschuiving in chirurgische technieken brengt met zich mee dat aios onvoldoende geschoold worden in complexe open chirurgische ingrepen, maar soms ook in de minimaal invasieve technieken. De opleiding is niet meer in staat om een allround uroloog af te leveren en zal dit ook met een nieuw curriculum niet kunnen bereiken. De eisen van de wereld om ons heen maken dit onmogelijk en hoewel dit voor veel zittende en waarschijnlijk ook aankomend urologen soms even slikken is, kunnen wij daar niet veel meer aan doen dan onze opleiding aanpassen aan de veranderende eisen.

Dit betekent waarschijnlijk een basisniveau voor allen en verdieping voor diegenen die hier behoefte aan hebben en er geschikt voor zijn. Voor sommige onderdelen van het vak zal verdieping tijdens de opleiding uiteindelijk waarschijnlijk niet voldoende zijn en zal de binnen de NVU moeizaam lopende discussie rond het Fellowship (of welke variant hierop dan ook) weer geactualiseerd moeten worden. De gang van zaken rond de certificering heeft hier ook mee te maken en laat zien dat er nog werk te verzetten is.

De minister heeft besloten te gaan korten op de financiële bijdrage aan het opleiden van nieuwe specialisten. $\mathrm{Na}$ moeizame onderhandelingen werd in 2013 door, toen nog, de Orde Medisch Specialisten (OMS) bereikt dat de medische vervolgopleidingen zelf, door middel van onder andere een gedifferentieerde korting van de opleidingsduur, de geëiste kortingen zouden ophoesten. Hiermee was een verlaging van de opleidingsvergoeding gemoeid van 29 miljoen euro in 2014 tot 90 miljoen euro in 2018, een reductie van de instroom met 100 plaatsen in 2015 en een geleidelijke invoering van een verkorting van de opleidingsduur, uiteindelijk met een half jaar bij $80 \%$ van de aios in 2022. Inmiddels is de 'taakstelling verkorting opleidingsduur' al bijgesteld naar gemiddeld zeven maanden bij $100 \%$ van de aios. Vanaf 1 april 2017 zal worden beoordeeld of de geplande bezuinigingen voor het volgende jaar gehaald worden. Een tussentijdse inventarisatie laat overigens zien dat de urologie waarschijnlijk redelijk op koers ligt. Om een en ander te 
realiseren, zijn centraal twee projecten gestart. De Nederlandse Federatie van Universitair Medische Centra (NFU) houdt zich bezig met het project 'Dedicated schakeljaar', de Federatie met het project 'individualisering opleidingsduur' waarover later meer. Om dit doel voor de opleiding Urologie te bereiken, werd door het Concilium de Commissie Korting Opleidingsduur (CKO) ingesteld. Deze commissie stelde vast dat er geen enkele reden is om te denken dat het ineens mogelijk is om de urologie in vijf jaar en vijf maanden onder de knie te krijgen. Wel blijken, al lange tijd, de meeste kandidaat-aios een voortraject te hebben doorlopen waarin zij al met een deel van de (met name algemene) competenties te maken hebben gekregen. Deze opgedane kennis en ervaring is zeker inzetbaar tijdens de opleiding en dient dan ook met kortere opleidingsperioden voor deze onderdelen gehonoreerd te worden. De winst is met name te boeken tijdens de vooropleiding Heelkunde die, om die reden, met een half jaar verkort kan worden. Korting op het urologisch deel van de opleiding is minder gewenst, gezien de grote hoeveelheid innovaties die het specialisme de laatste jaren heeft doorgemaakt.

Een ander hot item is de individualisering van de opleiding: de aios is zelf verantwoordelijk voor zijn opleiding, maar de opleiders zijn verantwoordelijk voor het aanbieden van, het toezicht houden op en het beoordelen van de aios. Theoretisch kan de aios delen van zijn opleiding in elke Onderwijs- en Opleidingsregio (OOR) bij elkaar sprokkelen, hij brengt immers zelf het geld hiervoor mee. Vanzelfsprekend geeft dit praktische en organisatorische problemen: voor de aios die moeilijk elke drie maanden kan verhuizen, maar ook voor de opleidersgroepen die, ondanks alle mooie woorden over productieneutraal opleiden, toch een zekere stabiliteit in hun bezetting nodig hebben. Hoewel een project als 'Opleiding in de etalage' in de urologie nog geen grote vlucht heeft genomen, zien wij toch geleidelijk aan assistenten om vakinhoudelijke, dan wel persoonlijke redenen, tijdens de opleiding van OOR switchen. Zeker omdat het om kleine aantallen assistenten en relatief veel opleidingsklinieken gaat, is de impact voor betrokken vakgroepen soms groot. Bovendien is het, ondanks een digitaal portfolio, vaak moeilijk om een beeld te krijgen van de status quo van betrokken assistent.

De nieuwe generatie aios is niet vergelijkbaar met de vroegere. Met de toename van het aantal vrouwen in de opleiding en in een situatie waarin de aios, vrijwel uniform, er één van een hardwerkend stel tweeverdienende ouders is, worden andere eisen gesteld aan de aios als persoon. Dit heeft gevolgen voor de opleiding: deze wordt steeds vaker in deeltijd gedaan, wordt onderbroken door zwangerschapsof ouderschapsverlof of zelfs door sabbaticals. Veel aios gaan de opleiding nog wel in met de gedachte om hun carrière na de opleiding voort te zetten in een 'topklinisch perifeer opleidingsziekenhuis', maar stellen hun ideeën tijdens de opleiding bij, onder invloed van diverse omstandigheden. De huidige opleiding is nog onvoldoende in staat om in te spelen op deze gevarieerde vraag.

\section{Commissie Herziening Curriculum}

De Commissie Herziening Curriculum is inmiddels, onder leiding van Eric Meuleman, aan de slag gegaan. Hoewel er nog sprake is van 'werk in uitvoering', is duidelijk dat ook in de urologie het principe van de EPA zijn intrede zal doen. De EPA ofwel Entrustable Professional Activity (in het Nederlands 'toevertrouwde handeling') beschrijft een domein dat in zijn geheel wordt beoordeeld door middel van het portfolio en een oordeel van de opleidersteamvergadering. Binnen een EPA zijn ook de algemene competenties ingebouwd en deze competenties worden dus meegewogen in het oordeel. Het is mogelijk een genuanceerd oordeel uit te spreken over de vraag in welke mate een bepaald domein aan de aios als zelfstandig opererend professional kan worden toevertrouwd. Met EPA's kan tegemoet gekomen worden aan het feit dat de visie van de huidige aios op hun carrière, na het beëindigen van de opleiding, aan verandering onderhevig is. Bovendien bieden de EPA's de mogelijkheid om de opleiding in een 'eigen tempo' (zij het binnen de gestelde termijn) te doorlopen, en zo eventueel ruimte te verdienen voor verdiepingsstages en individualisering van de opleiding.

\section{Capaciteitsorgaan}

Het Capaciteitsorgaan heeft onlangs een uitgebreide analyse van de behoefte aan opleidingsplaatsen voor de komende jaren gepresenteerd. Het betreft een zeer lijvig en ogenschijnlijk goed onderbouwd rapport dat flinke verschuivingen toont in het aantal op te leiden aios. Hoewel het daarmee natuurlijk nog steeds mogelijk is dat we over tien jaar moeten constateren dat men er volkomen naast zat, mag ervan worden uitgegaan dat het aantal van 18-21 instromende aios per jaar dat genoemd wordt, de norm zal worden.

Dit jaar is het nog gelukt om de wensen van de NVU bij Stichting BOLS, de stichting die de minister adviseert, geaccepteerd te krijgen; in de toekomst zal dit steeds moeilijker worden. Dit kan ook gevolgen hebben voor de verdeling van de aios over de OOR's. Met deze kleine aantallen assistenten is het ook de vraag hoeveel opleidingsklinieken er nu eigenlijk nodig zijn in Nederland. Een opleidingsklimaat creëren voor één aios is niet erg kosteneffectief en vraagt veel inzet, hoewel de aios waarschijnlijk veel kan leren. De druk op academische ziekenhuizen om zich meer op hun derdelijnstaken te concentreren, zal eveneens verschuivingen in de opleiding met zich meebrengen. De traditionele verhouding twee jaar academisch en twee jaar perifeer, zal waarschijnlijk minder een automatisme zijn. 
Bovendien zullen opleidingsklinieken, afhankelijk van hun profiel, waarschijnlijk steeds vaker slechts delen van de opleiding mogen verzorgen. Ook de eerdergenoemde verdiepingsstages binnen de reguliere opleiding brengen weer nieuwe vragen met zich mee. Moet zo'n verdiepingsstage binnen een erkende opleidingsinstelling plaatsvinden of zou het ook mogelijk moeten zijn de stage, binnen het kader van de opleiding, te detacheren aan expertisecentra zonder opleidingsbevoegdheid?

\section{Visitaties}

Bovenstaande ontwikkelingen zijn reeds gaande en het eind ervan is nog niet in zicht. Hoewel alle opleidingsregio's regionale opleidingsplannen hebben en er regelmatig opleidingsbesprekingen zijn, zullen in toenemende mate eisen aan de samenwerking worden gesteld. Dit zal ook gevolgen hebben voor de visitaties. Regionale visitaties zullen het logische gevolg zijn van deze verregaande samenwerking, evenals verticale visitaties van opleidingsklinieken, waarbij in één kliniek meerdere opleidingen tegelijk gevisiteerd worden.

\section{En zo verder!}

$\mathrm{Al}$ met al moge duidelijk zijn dat, in tegenstelling tot het verhaal van Guus Lycklama à Nijeholt, waarin vol trots kan worden geschreven over behaalde resultaten, de toekomst, zoals gebruikelijk, nog geschreven moet worden. Een groot deel van de toekomst wordt door anderen bepaald, de Urologie heeft echter bewezen binnen deze beperkingen haar eigen agenda goed te kunnen invullen. Aan de NVU, en met name het Concilium, de taak dit ook de komende jaren weer te bewijzen.

Open Access This article is distributed under the terms of the Creative Commons Attribution 4.0 International License (http:// creativecommons.org/licenses/by/4.0/), which permits unrestricted use, distribution, and reproduction in any medium, provided you give appropriate credit to the original author(s) and the source, provide a link to the Creative Commons license, and indicate if changes were made.

\section{Literatuur}

1. Schout BMA, Vries AH de, Koldewijn EL., et al. Rapport training in urology. 1e fase implementatie 2012-2013: 40-uren project. UOI/NVU; Stichting Opleiding Medici; 2013.

prof. dr. A.A.B. Lycklama à Nijeholt uroloog

dr. W. Hirdes uroloog 